\title{
Jan-Christoph Herrmann, Der Wendenkreuzzug von
}

\section{7}

Europäische Hochschulschriften, Reihe III: Geschichte und ihre

Hilfswissenschaften, Bd. 1085, Francfort sur le Main, Peter Lang, 2011, 261 pages

\section{Sylvain Gouguenheim}

\section{OpenEdition}

\section{Journals}

Édition électronique

URL : http://journals.openedition.org/ifha/7544

DOI : 10.4000/ifha.7544

ISSN : 2198-8943

\section{Éditeur}

IFRA - Institut franco-allemand (sciences historiques et sociales)

\section{Référence électronique}

Sylvain Gouguenheim, « Jan-Christoph Herrmann, Der Wendenkreuzzug von 1747 », Revue de l'IFHA [En ligne], Date de recension, mis en ligne le 15 décembre 2013, consulté le 22 septembre 2020. URL http://journals.openedition.org/ifha/7544 ; DOI : https://doi.org/10.4000/ifha.7544

Ce document a été généré automatiquement le 22 septembre 2020

(C)IFHA 


\section{Jan-Christoph Herrmann, Der Wendenkreuzzug von 1147}

Europäische Hochschulschriften, Reihe III: Geschichte und ihre Hilfswissenschaften, Bd. 1085, Francfort sur le Main, Peter Lang, 2011, 261 pages

\section{Sylvain Gouguenheim}

La Croisade des Wendes de 1147 est principalement connue en raison du rôle qu'y joua la prédication de saint Bernard et parce qu'elle contribua à ouvrir les marches orientales de l'empire à la colonisation allemande. J.-C. Herrmann se propose de l'étudier sous tous ses aspects, en insistant sur ce qui la précéda et en s'interrogeant sur le sens qu'il convient de lui donner. Le résultat est présenté sous la forme de trois grands chapitres, de taille très inégale : 100 pages sont consacrées à la "préhistoire » de la Croisade, 30 à la Croisade elle-même et 78 à son analyse. La division interne des deux premiers chapitres est souvent très événementielle et se déploie chronologiquement; le chapitre analytique final repose largement sur une juxtaposition de données biographiques consacrées aux grands protagonistes de l'entreprise ainsi qu'à des Croisés moins connus. La Chronique des Slaves d'Helmold de Bosau fait l'objet d'une section particulière. L'ouvrage sacrifie largement à un exposé événementiel et tourne parfois au simple catalogue de rapides biographies ou à la présentation de fiches juxtaposées. D’un autre côté, la plupart des questions que l'on se pose sont abordées.

Le très long chapitre consacré à la préhistoire propose un rappel de la naissance de l'idée de Croisade, présente le peuplement slave à l'est de l'Elbe et détaille le contenu de leur religion. On a là des pages intéressantes et précises. Le cours des événements est ensuite abordé, d'Otton III à Henri II et son alliance avec les Lutices, puis vient une très longue présentation de la puissance bi-séculaire des Lutices et de leur révolte, jusqu'à la guerre entreprise par Henri IV et à l'action de Lothaire de Supplinburg.

Abordant la croisade wende elle-même (p. 122), l'auteur en indique les sources et en expose le déroulement chronologique. Puis vient le chapitre de synthèse, 
essentiellement consacré à la présentation des grands protagonistes (Henri le Lion, Albert l'Ours, l'évêque Anselme d'Havelberg, Wibald de Stavelot, Conrad de Wettin...).

Des conclusions de l'auteur on retiendra la prédominance des motifs politiques ayant animé les Croisés (venus de l'empire ou des royaumes voisins ,Pologne ou Danemark), la « décimation» du peuple wende, qui n'a toutefois pas disparu mais dont la culture a sombré - ce que l'auteur impute à la Croisade, mais les Wendes ne disposant pas d'écriture leur culture ne pouvait espérer résister à toute confrontation - même pacifique - avec des voisins dotés de cet outil, sauf à l'adopter. Il insiste également sur l'importance de l'eschatologie dans la prédication de saint Bernard (illustrée par l'adoption du symbole de la Croix surmontant le cercle terrestre), la montée en puissance de l'évêché d'Havelberg et le double processus qui suivit la Croisade, de colonisation et d'acculturation.

Des oublis ou des manques surprennent parfois : la réflexion initiale sur la naissance de l'idée de Croisade en reste largement tributaire de C. Erdmann et les travaux récents sur ce sujet ou sur les Croisades en général sont absents - y compris de la bibliographie où ni $\mathrm{C}$. Tyerman, ni $\mathrm{A}$. Demurger, ni Th. Deswartes ou M. Bull n'apparaissent. Le thème de la colonisation allemande qui retient l'auteur ne le conduit pas à citer le livre de Ch. Higounet.

L'ouvrage s'achève par une sélection de textes en latin accompagnés de leur traduction et d'un index. 12 cartes parsèment l'ouvrage : toutes utiles en théorie mais pas toutes suffisamment lisibles, vu le format du livre ou l'origine de ces cartes parfois simplement issues d'Atlas (sans indication de provenance).

$\mathrm{Au}$ total le livre n'apporte pas vraiment de surprise dans ses conclusions mais permet de faire le point sur le détail des événements, des personnages et des questions relatives à la Croisade wende.

\section{INDEX}

Index chronologique : Mittelalter

Thèmes : Geschichte des Religiösen, Militärgeschichte

\section{AUTEUR \\ SYLVAIN GOUGUENHEIM}

ENS de Lyon 